\title{
Future strategies to enhance kidney preservation in upper urinary tract urothelial carcinoma
}

\author{
Meredith Metcalf, Phillip M. Pierorazio
}

The James Buchanan Brady Urological Institute and Department of Urology, Johns Hopkins University School of Medicine, Baltimore, MD, USA Contributions: (I) Conception and design: All authors; (II) Administrative support: All authors; (III) Provision of study material or patients: All authors; (IV) Collection and assembly of data: All authors; (V) Data analysis and interpretation: All authors; (VI) Manuscript writing: All authors; (VII) Final approval of manuscript: All authors.

Correspondence to: Phillip M. Pierorazio. The James Buchanan Brady Urological Institute and Department of Urology, Johns Hopkins University School of Medicine, Baltimore, MD, USA. Email: philpierorazio@jhmi.edu.

\begin{abstract}
Though radical nephroureterectomy remains the gold standard treatment for high grade or invasive disease in upper tract urothelial cancer (UTUC), kidney-sparing surgery has become preferred for low risk disease, in order to minimize morbidity and preserve renal function. Many methods exist for endoscopic management, whether via an antegrade percutaneous or retrograde ureteroscopic approach, including electroresection, laser ablation, and fulguration. There has been an increase in use of adjuvant intracavitary therapy, predominantly using mitomycin and bacillus Calmette-Guerin (BCG), to reduce recurrence after primary endoscopic management for noninvasive tumors, although efficacy remains questionable. Intraluminal BCG has additionally been used for primary treatment of CIS in the upper tract, with around $50 \%$ success. Newer investigations include use of narrow band imaging or photodynamic diagnosis with ureteroscopy to improve visualization during diagnosis and treatment. Genomic characterization may improve selection for kidney-sparing surgery as well as identify actionable mutations for systemic therapy. The evolution in adjuvant management has seen strategies to increase the dwell time and the urothelial contact of intraluminal agents. Lastly, chemoablation using a hydrogel for sustained effect of mitomycin is under investigation with promising early results. Continued expansion of the armamentarium available and better identification and characterization of tumors ideal for organsparing treatment will further improve kidney preservation in UTUC.
\end{abstract}

Keywords: Upper tract urothelial carcinoma (UTUC); kidney-sparing; organ preservation

Submitted Oct 04, 2019. Accepted for publication Nov 11, 2019.

doi: 10.21037/tau.2019.11.09

View this article at: http://dx.doi.org/10.21037/tau.2019.11.09

Upper tract urothelial cancer (UTUC) accounts for 5\% to $10 \%$ of all urothelial carcinoma $(1,2)$. First described in 1934 (3), radical nephroureterectomy has long been the gold standard treatment for any upper urinary tract tumor (4). The original utilization of kidney-sparing approaches, in lieu of nephroureterectomy, was targeted to highly selected patients with imperative indications such as sparse renal reserve (solitary kidney or severe baseline renal impairment), bilateral disease, or coexistent morbidity precluding radical extirpative surgery. Over time, particularly with improvement of endoscopic techniques for both diagnosis and management, organ-sparing has been applied more broadly. Kidney-sparing is now the recommended approach in low risk cancers and in those with isolated distal ureteral tumors, as well as in patients with severe renal insufficiency or a solitary kidney on a caseby-case basis (5).

\section{Current approach to kidney preservation}

The goal of organ-sparing treatment is to avoid the morbidity of a radical operation while maintaining 
equivalent oncologic outcomes. The need for development of therapies for organ-preservation for UTUC has been recognized for 30 years (6). The rates of minor and major complications after nephroureterectomy may be as high as $40 \%$ and $29 \%$, respectively $(7,8)$, and are similar among open, laparoscopic, and robotic approaches (9). A population-based sample found the 90 -day mortality to be $4.4 \%$ (10). Kidney preservation in upper tract cancer is also desirable due to unique concerns of nephroureterectomy, such as the risk for severe renal insufficiency and subsequent cardiovascular events (11). A retrospective review by Kaag et al. showed a mean decline in estimated glomerular filtration rate (eGFR) of $24 \%$ after nephroureterectomy, with over half of patients with a baseline eGFR above $60 \mathrm{~mL} / \mathrm{min}$ falling below $60 \mathrm{~mL} / \mathrm{min}$ postoperatively (12). Similarly, Raman et al found that around one quarter of all patients experienced a decline in eGFR below $60 \mathrm{~mL} / \mathrm{min}$, with around $15 \%$ falling below $45 \mathrm{~mL} / \mathrm{min}$ after nephroureterectomy. As expected, renal functional outcomes have been shown to be superior with kidney-sparing approaches (13). This complication of renal functional decline is compounded by the morbidity related to $\mathrm{CKD}$, with an overall mortality almost three times that of the population without CKD and over $50 \%$ rate of hospitalization per patient-year (14).

Several reports have now shown that in addition to avoiding the complications of nephroureterectomy, initial endoscopic management has comparable oncologic outcomes to nephroureterectomy in carefully selected patients, particularly for low grade disease (15). Endoscopic management of UTUC was initially utilized for imperative indications, such as solitary kidney, bilateral disease, or coexistent morbidity prohibiting nephroureterectomy (16). Over time, coupled with improved diagnostic techniques that more reliably distinguish low grade disease, endoscopic management has been applied more broadly $(17,18)$. Current recommendations for first line treatment of low risk disease, defined as unifocal tumors $<1 \mathrm{~cm}$ in size with low grade cytology and biopsy and no invasive aspect on CT, are for organ-sparing approaches such as endoscopic ablation, which can be performed retrograde ureteroscopically or antegrade percutaneously (5). However, series of patients managed endoscopically showed high recurrence rates (19-21) and rates of salvage nephroureterectomy ranging from $16.7 \%$ in low grade disease to $28.6 \%$ in high grade (22).

Due to high recurrence rates, endoscopic management evolved to include adjuvant treatment, as intraluminal therapies for non-muscle invasive bladder cancer were extrapolated to the upper urinary tract. Most reports are from small case series, with the majority using bacillus Calmette-Guerin (BCG) and mitomycin, although epirubicin $(23,24)$, adriamycin (25), thiotepa (26-28), and BCG with interferon $(29,30)$ have also been reported. Instillation has been attempted retrograde via vesicoureteral reflux (31), via double-J stents with the patient in Trendelenburg (32), and via an open-ended ureteral catheter (27), as well as antegrade via a nephrostomy tube (23). Intracavitary therapy has been utilized as adjuvant therapy after endoscopic resection or ablation of papillary disease (Table 1) as well as for primary treatment of carcinoma in situ (CIS) in the upper urinary tract (Table 2).

Mitomycin has been used as adjuvant therapy postoperatively after endoscopic management. Over the years, endoscopic techniques have included ureteroscopic laser ablation or fulguration and percutaneous resection (with or without fulguration or laser ablation). For example, a retrospective review of 19 patients (20 renal units) treated with adjuvant postoperative mitomycin after laser ablation of ureteral or renal pelvic tumors found a cancer-free survival of $65 \%$ (recurrence rate $35 \%$ ), and $85 \%$ remained disease-free without nephroureterectomy at last follow up with stable renal function in all patients (42). Regimens vary slightly for upper tract instillation of mitomycin, with doses of $40 \mathrm{mg}$ being dissolved in 30,40 , or $1,000 \mathrm{~mL}$ of saline or $5 \mathrm{mg}$ in $20 \mathrm{~mL}$ saline. Ureteral integrity may be verified by a retrograde pyelogram or antegrade nephrostogram prior to instillation; other authors have waited until gross hematuria resolves, usually 1-3 days postoperatively. The solution is infused slowly, with reported rates of $1 \mathrm{~mL} / \mathrm{min}$. For instillation via a ureteral catheter, the catheter can be clamped after administration for around 30 minutes prior to gravity drainage.

Additionally, adjuvant therapy with mitomycin has been evaluated utilizing an induction and maintenance course, the largest series to date of adjuvant mitomycin and the only one with more than 20 patients (21). In this series, 28 renal units were treated $(75 \%$ of which had low grade UTUC), using $40 \mathrm{mg}$ in $20 \mathrm{~mL}$ saline instilled either via ureteral catheter or via nephrostomy tube over two hours. Six weekly instillations were performed for induction, with maintenance done either once monthly for at least three months or three weekly instillations following the Southwest Oncology Group BCG protocol (52), with 61\% completing the first maintenance course, $36 \%$ completing the second, $18 \%$ completing up to the fifth, and $7 \%$ completing a sixth maintenance course. The recurrence 


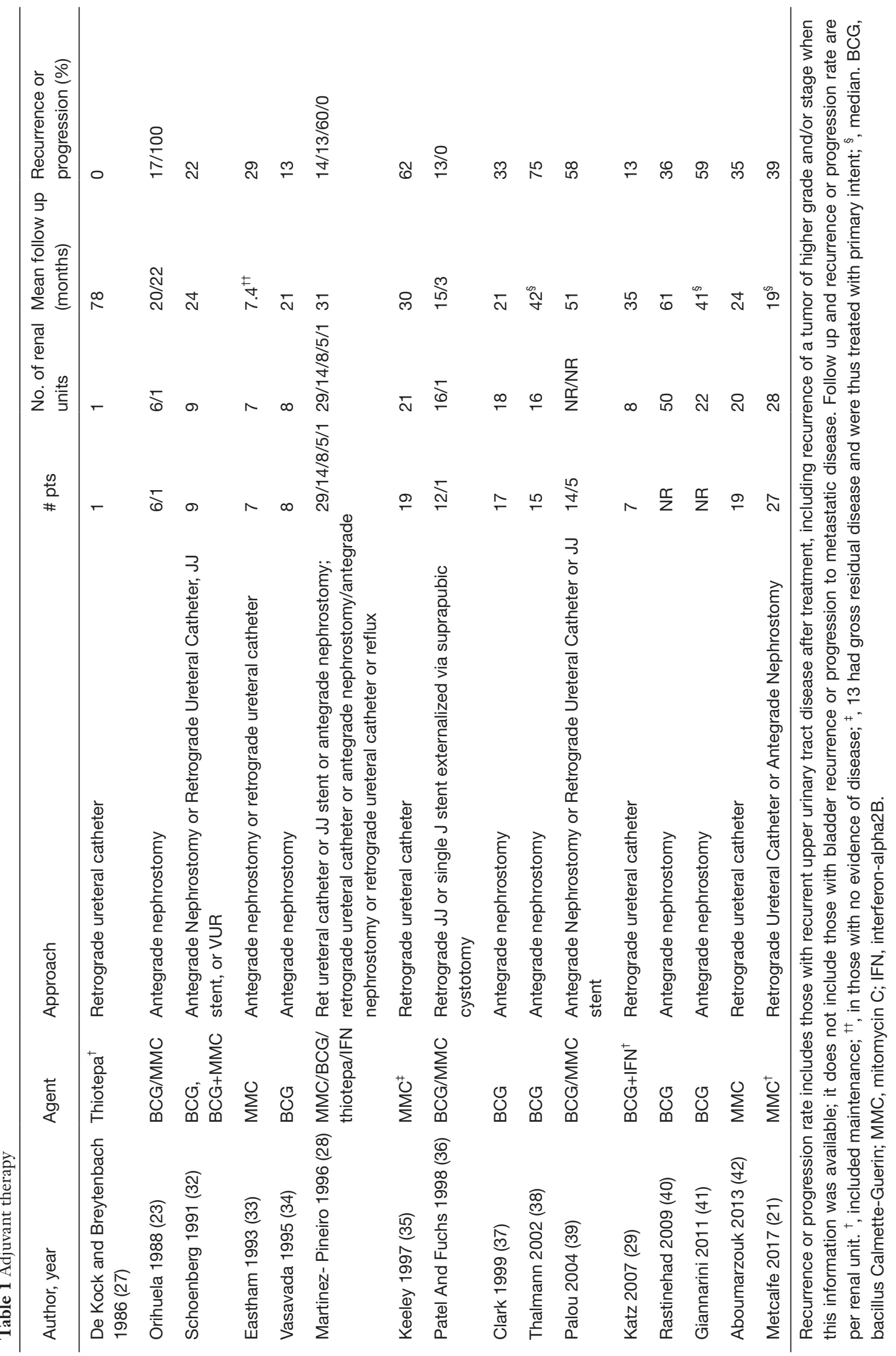


Table 2 BCG as primary therapy for cis

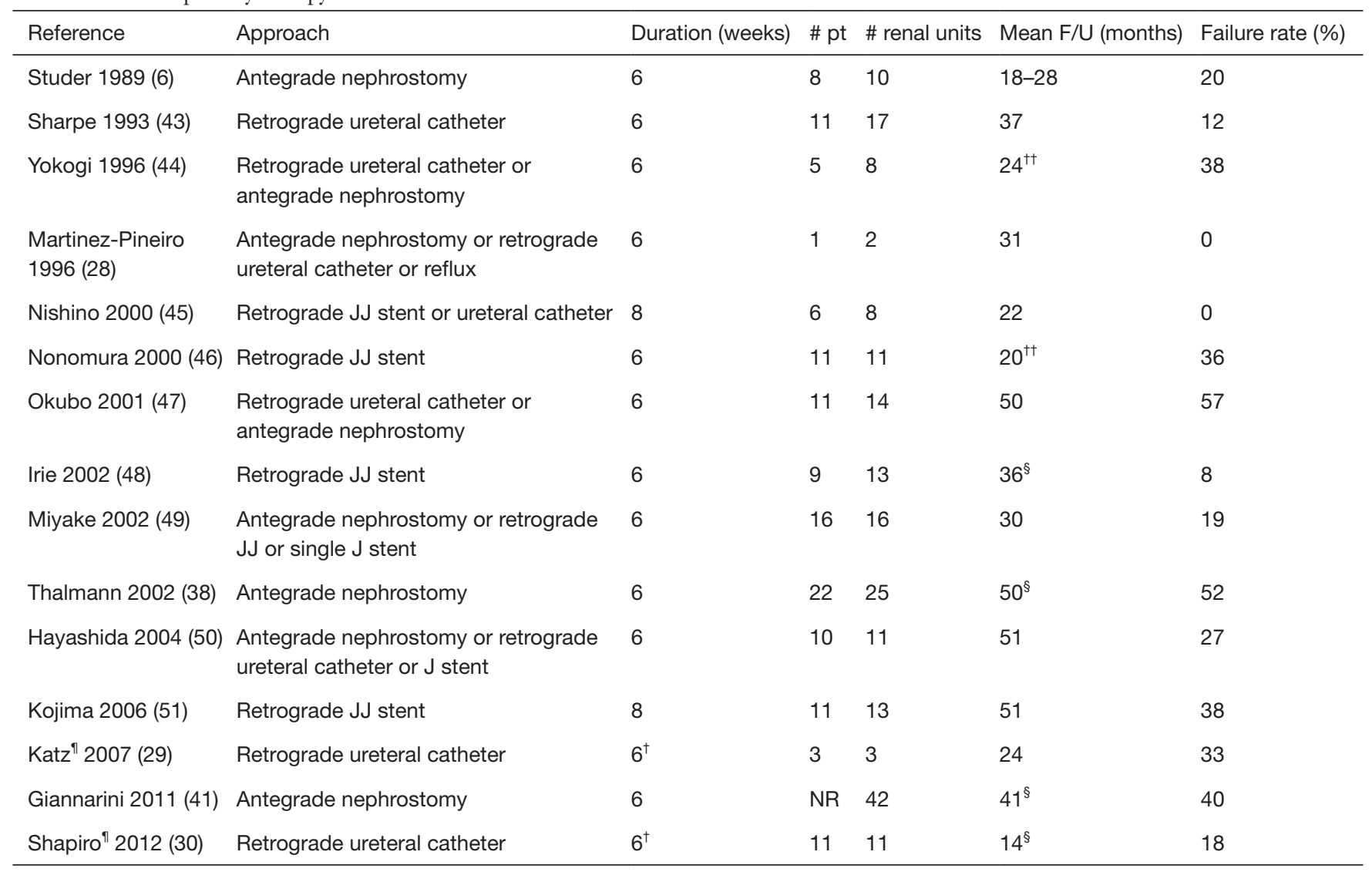

Failure rate includes those with persistent disease and those with upper urinary tract recurrence or progression after treatment. Follow up and failure rate are per renal unit. ${ }^{\dagger}$, included maintenance; ${ }^{\dagger \dagger}$, in those with no evidence of disease; ${ }^{\S}$, median; ${ }^{~ ", ~ b a c i l l u s ~ C a l m e t t e-G u e r i n ~}$ $(B C G)+$ interferon-alpha2B (IFN).

rate was $39 \%$ at a median follow up of 19 months. The 3 -year progression-free survival rate was $80 \%$, with $18 \%$ of patients ultimately undergoing nephroureterectomy.

The first use of upper tract instillation of BCG for the cure of upper tract CIS was by Studer et al. in 1989 (6), after a report by Herr of intravesical BCG in a patient after resection and reconstruction of a pelvic kidney with pyelovesical anastomosis for persistent CIS of the renal pelvis in 1985 (53). Six patients with a history of urothelial cancer and unfit or unwilling to undergo major surgery who had positive cytology with negative bladder and prostatic urethral biopsies were treated with BCG perfusions as a course of 6 weekly instillations via nephrostomy tube, where the BCG was dripped in by gravity at approximately $1 \mathrm{~mL} / \mathrm{min}$. In four patients, cytology converted to negative and remained as such for 18-28 months; in one patient with bilateral disease, cytology converted to negative after several courses of BCG and remained so at 18 months; in one a papillary tumor persisted but CIS disappeared. Since that time, several series have reported outcomes with antegrade or retrograde instillation of BCG for cure of CIS (Table 2). As with mitomycin, various protocols have been described. Generally, the solution is administered slowly, usually no more than $1 \mathrm{~mL} / \mathrm{min}$, and all but two series used six weekly instillations, similar to its use for bladder cancer. Various doses, in volumes ranging from 40 to $250 \mathrm{~mL}$, have been used. The initial positive response rates ranged from $63-100 \%$ with upper tract recurrence in up to half.

Adjuvant BCG has also been utilized after endoscopic treatment of papillary disease. Several small series have reported recurrence rates from $13 \%$ up to $75 \%$ (Table 1). In a review of patients treated with BCG for either cure of CIS or as adjuvant therapy after endoscopic treatment of $\mathrm{Ta} / \mathrm{T} 1$ tumors, there was a $59 \%$ recurrence rate and $41 \%$ progression rate in patients with $\mathrm{Ta} / \mathrm{T} 1$ tumors, with $23 \%$ going on to nephroureterectomy, which was worse than 
those treated with curative intent for CIS (41). While about half of renal units with CIS may be cured by BCG, there is no definitive evidence for the efficacy of adjuvant topical chemotherapy or immunotherapy after endoscopic ablation of T1/Ta tumors $(40,41,54,55)$.

Several challenges remain in attempts to translate the success of intravesical immunotherapy and chemotherapy in NMIBC to UTUC. Endoscopic resection or ablation may be incomplete, resulting in adjuvant therapies treating more residual disease. Accurate identification and staging remain elusive. Lastly, achieving adequate dwell time in the upper urinary tract is a problem for intraluminal therapy. Additional techniques continue to be developed to address challenges in nephron-sparing for upper tract urothelial carcinoma.

\section{Future strategies}

There are several diagnostic difficulties with upper tract neoplasms. Endoscopic localization of the tumor may be difficult, and there may be no readily visible lesion with CIS. The varying diagnostic criteria for CIS used in the literature reflects this diagnostic difficulty (56). Narrow band imaging (NBI) may improve patient selection for nephron-sparing approaches by enhancing imaging at diagnosis. It may also benefit endoscopic treatment by defining the borders of lesions or helping identify additional tumors. In a review of 27 patients who underwent standard white light as well as NBI flexible ureteroscopy, NBI provided additional information in $38.4 \%$ of patients by allowing detection of additional tumors or recognition of the lesion's borders (57).

Photodynamic diagnosis (PDD) has also been used to improve visualization of lesions in the upper urinary tract with oral administration of 5-Aminolevulinic Acid prior to ureteroscopy (58). In one review of 26 biopsies performed for suspicious upper tract lesions, $38.5 \%$ of biopsies were taken from lesions seen only under blue light, and $70 \%$ of these were malignant (59). A similar review of ureteroscopy of 106 renal units found that PDD detected significantly more CIS and dysplasia than white light and also had higher sensitivity (60).

When tumors are visualized, grade is commonly used as a surrogate for stage to determine which patients should get nephroureterectomy due to difficulty with determining stage via biopsy.

However, the biologic basis for upper tract CIS and papillary tumors as well as their distinction from bladder cancer continue to be investigated and may provide more guidance than biopsy or cytology alone on which tumors are most appropriate for kidney-sparing approaches. Complete genomic characterization of UTUC has begun (61-63). Some biologic distinctions from bladder cancer have been detailed, such as more common microsatellite instability in UTUC $(61,64)$ and more common and more extensive promoter hypermethylation (65). Although a similar array of genes was mutated in one analysis of 59 high grade upper tract tumors and 102 bladder tumors, the prevalence of mutations was different (61). This finding was corroborated in a separate analysis of 195 upper tract and 454 bladder cancer samples. Specifically, there was a higher rate of FGFR3- and HRAS-altered high grade tumors in the upper tract compared to bladder, possibly consistent with a model in which low grade tumors more frequently progress to high grade invasive disease when they arise in the upper tract (61). It may also be that UTUC fits predominantly within the "luminal" subtype identified in bladder cancer (66), which shows a similar FGFR3 mutation frequency (67).

Further work has been done using whole exome sequencing and gene expression profiling to characterize and group UTUC into expression-based subtypes, similar to work that has been done in bladder cancer (62). In this analysis based on 31 tumors there was an even higher rate of FGFR3 mutations (74\% compared to $36 \%$ in the prior study), which also was present in $60 \%$ of high grade tumors. Genes related to DNA damage repair and chromatinmodification appear to play a critical role for UTUC based on whole exome sequencing. Also in this analysis, samples segregated into four subtypes that were correlated with clinical variables such as grade, stage, and recurrence, with some clusters having no bladder recurrence.

In the largest genomic study of UTUC to date, over half of the tumors in the cohort of 195 patients had potentially actionable genomic alterations (63). By comparing UTUC specimens to subsequent bladder tumors in the same patient in a subgroup of 29 patients, it was determined that bladder recurrences were clonally related to upper tract disease. Additionally, alterations in FGFR3, KDM6A, CCND1, and TP53 increased the risk of recurrence in the bladder.

As the above-mentioned studies indicate, there has been a great deal of recent genomics and genetics work for UTUC. However, genomic analyses in these cases were from samples from radical nephroureterectomy. To translate this developing knowledge into potential organ-sparing therapy, testing would need to be performed on specimens prior to extirpative surgery. In an effort to determine the feasibility of next-generation sequencing on ureteroscopic 
specimens, Bagrodia et al. obtained biopsies of upper tract tumors via ureteroscopic techniques then extracted and sequenced tumor DNA (68). In their evaluation, $92 \%$ had adequate material for sequencing. The molecular landscape was similar to a cohort previously analyzed by the authors as well as to other reports. The biopsies were then compared to nephroureterectomy specimens from the same patient in twelve cases. For the patients not receiving neoadjuvant chemotherapy, $71 \%$ of all mutations and $92 \%$ of likely pathogenic mutations were present in both specimens, with $100 \%$ concordance in $40 \%$. The concordance was lower for patients receiving neoadjuvant chemotherapy $(53 \%$ of all and $62 \%$ of likely pathogenic). However, $82 \%$ of the likely oncogenic mutations in the nephroureterectomy specimens were found in the prior biopsies. In the future, urinary cellfree DNA may also be able to provide similar information. While these findings are not yet diagnostic or actionable, the field is evolving perhaps to be able to use these findings to promote kidney-sparing approaches to UTUC.

Another evolving facet in the management of UTUC is in the approach taken towards intraluminal therapy. The adequacy of simple instillation of mitomycin has been in question since early feasibility studies in the upper tract $(33,35)$, because exposure time to urothelium is critically important for efficacy with mitomycin $(69,70)$. Urine production and ureteral peristalsis may both contribute to diminished efficacy in the upper urinary tract by reducing dwell time. One approach to prolong drug retention in the upper tract is sustained release of chemotherapy using drugeluting stents. Barros et al combined hydrogel technology with ureteral stents in the development of a biodegradable drug-eluting stent (71). Biodegradable ureteral stents were prepared and then impregnated with chemotherapeutics (paclitazel, epirubicin, doxorubicin, and gemcitabine). In an in vitro artificial acidic urine solution with sink conditions, almost $50 \%$ of the drug was released by four hours; there was then sustained release of the remaining drug until around 72 hours, and the stent degraded after 9 days. The impregnated stent also showed in vitro potency in urothelial cancer lines, with the amount of drug released higher than the half maximal inhibitory concentration (IC50, a measure of the concentration needed to inhibit cell survival) of the cancer cells but lower than that of control cells. The viability of cancer cells decreased around 50\% after 72 hours in contact with drug-loaded stents, and killing efficacy of the impregnated stent was confirmed with microscopy.

Bilayer swellable drug-eluting stents have also been developed to try to take advantage of sustained delivery as well as improve apposition with the urothelium (72). In this design, a drug-impregnated hydrogel swells with contact with urine to augment contact with the urothelium, minimizing wash out from urine flow; this also increases transfer through the impermeable urothelium. The stents were loaded with mitomycin for evaluation of in vitro, $e x$ vivo, and in vivo drug release and transfer using a porcine model, with increased drug release over seven days and increased drug transfer to the explanted porcine ureter with use of the hydrogel. The release of mitomycin was also found to be modifiable based on parameters of the saturated amount of drug and thickness of the polymer coating of the stent. A decrease in human bladder stroma fibroblast cell growth in the presence of hydrogel eluted mitomycin culture medium was also shown. Lastly, the prototype was evaluated in vivo in a porcine model that showed good apposition of the hydrogel to the ureter and mitomycin in the targeted portion of the ureter.

UGN101 (MITOGEL ${ }^{\mathrm{TM}}$ ) likewise seeks to overcome the obstacles of upper tract instillation as well as the difficulty of complete endoscopic ablation. This investigational hydrogel formulation of mitomycin is liquid when injected in retrograde fashion into the upper urinary tract, becomes a gel, and slowly dissolves with urine, resulting in sustained release of the drug to the urothelium. It is being investigated, however, as primary chemoablation for tumors in situ, rather than adjuvant therapy once the tumor has been resected. The first use of mitomycin for the chemoablation of UTUC was reported by Smith et al. in 1987 in the treatment of upper tract recurrence in two patients with a history of low grade bladder cancer was (73). Both had low grade noninvasive bladder cancer overlying a ureteral orifice, with recurrence in the ipsilateral ureter. Vesicoureteral reflux was confirmed with a cystogram, and intravesical mitomycin was used to treat the ureteral tumors, with complete resolution of the tumors confirmed with biopsy and no upper tract recurrence at two years. Now a clinical trial evaluating the effectiveness of 6 weekly instillations of UGN101 for patients with biopsy proven unilateral low grade UTUC has completed enrollment (NCT02793128). In the initial interim analysis (74), 57\% of patients in the intention to treat cohort had a complete response, defined as negative ureteroscopic evaluation and negative wash cytology at approximately 5 weeks after the instillation. For patients with a complete response, treatment is continued with once monthly maintenance instillations for up to eleven months. Subsequent topline 
data showed all evaluated patients with a complete response remained disease-free at six months. While long-term durability has yet to be reported, the short-term results are promising as a potentially new therapeutic option for low grade UTUC.

\section{Conclusions}

As more insight has been gained into risk classification for UTUC, applicability of kidney-sparing treatment has expanded. Moving forward, continued expansion of the armamentarium available and better identification and characterization of tumors ideal for organ-sparing treatment will further improve kidney preservation in UTUC.

\section{Acknowledgments}

Funding: None.

\section{Footnote}

Provenance and Peer Review: This article was commissioned by the Guest Editors (John J. Knoedler and Jay D. Raman) for the series "Upper-Tract Urothelial Carcinoma: Current State and Future Directions" published in Translational Andrology and Urology. The article was sent for external peer review organized by the Guest Editors and the editorial office.

Conflicts of Interest: Both authors have completed the ICMJE uniform disclosure form (available at http:// dx.doi.org/10.21037/tau.2019.11.09). The series "UpperTract Urothelial Carcinoma: Current State and Future Directions" was commissioned by the editorial office without any funding or sponsorship. PMP reports grants from Urogen Pharma as site PI for the Olympus trial and personal fees from serving on the scientific advisory board of Urogen Pharma. The authors have no other conflicts of interest to declare.

Ethical Statement: The authors are accountable for all aspects of the work in ensuring that questions related to the accuracy or integrity of any part of the work are appropriately investigated and resolved.

Open Access Statement: This is an Open Access article distributed in accordance with the Creative Commons Attribution-NonCommercial-NoDerivs 4.0 International
License (CC BY-NC-ND 4.0), which permits the noncommercial replication and distribution of the article with the strict proviso that no changes or edits are made and the original work is properly cited (including links to both the formal publication through the relevant DOI and the license). See: https://creativecommons.org/licenses/by-nc-nd/4.0/.

\section{References}

1. Siegel RL, Miller KD, Jemal A. Cancer statistics, 2016. CA Cancer J Clin 2016;66:7-30.

2. Munoz JJ, Ellison LM. Upper tract urothelial neoplasms: Incidence and survival during the last 2 decades. J Urol 2000;164:1523-5.

3. Kimball FN, Ferris HW. Papillomatous Tumor of the Renal Pelvis Associated with Similar Tumors of the Ureter and Bladder. Review of Literature and Report of Two Cases. J Urol 1934;31:257-304.

4. Cummings KB. Nephroureterectomy: Rationale in the management of transitional cell carcinoma of the upper urinary tract. Urol Clin North Am 1980;7:569-78.

5. Rouprêt M, Babjuk M, Burger M, et al. European Association of Urology Guidelines on Upper Urinary Tract Urothelial Carcinoma: 2017 Update. Eur Urol 2018;73:111-22.

6. Studer UE, Casanova G, Kraft R, et al. Percutaneous Bacillus Calmette-Guerin Perfusion of the Upper Urinary Tract for Carcinoma in Situ. J Urol 1989;142:975-7.

7. Tsujihata $\mathrm{M}$, Nonomura $\mathrm{N}$, Tsujimura A, et al. Laparoscopic nephroureterectomy for upper tract transitional cell carcinoma: Comparison of laparoscopic and open surgery. Eur Urol 2006;49:332-6.

8. Shalhav AL, Dunn MD, Portis AJ, et al. Laparoscopic nephroureterectomy for upper tract transitional cell cancer: The Washington University experience. J Urol 2000;163:1100-4.

9. Lee H, Kim HJ, Lee SE, et al. non-metastatic upper-tract urothelial carcinoma. PLoS One 2019;14:e0210401.

10. Jeldres C, Sun M, Isbarn H, et al. A Populationbased Assessment of Perioperative Mortality After Nephroureterectomy for Upper-tract Urothelial Carcinoma. Urology 2010;75:315-20.

11. Lin SY, Lin CL, Chang CH, et al. Risk of acute myocardial infarction in upper tract urothelial carcinoma patients receiving radical nephroureterectomy: A population-based cohort study. Oncotarget 2017;8:79498-506.

12. Kaag MG, O'Malley RL, O'Malley P, et al. Changes in renal function following nephroureterectomy may 
affect the use of perioperative chemotherapy. Eur Urol 2010;58:581-7.

13. Silberstein JL, Power NE, Savage C, et al. Renal function and oncologic outcomes of parenchymal sparing ureteral resection versus radical nephroureterectomy for upper tract urothelial carcinoma. J Urol 2012;187:429-34.

14. 2018 USRDS annual data report: Epidemiology of kidney disease in the United States. United States Renal Data System. Bethesda, MD; 2018.

15. Seisen T, Peyronnet B, Dominguez-Escrig JL, et al. Oncologic Outcomes of Kidney-sparing Surgery Versus Radical Nephroureterectomy for Upper Tract Urothelial Carcinoma: A Systematic Review by the EAU Non-muscle Invasive Bladder Cancer Guidelines Panel. Eur Urol 2016;70:1052-68.

16. Streem SB. Percutaneous management of uppertract transitional cell carcinoma. Urol Clin North Am 1995;22:221-9.

17. Chen GL, Bagley D. Ureteroscopic management of upper tract transitional cell carcinoma in patients with normal contralateral kidneys. J Urol 2000;164:1173-6.

18. Thompson RH, Krambeck AE, Lohse CM, et al. Endoscopic Management of Upper Tract Transitional Cell Carcinoma in Patients with Normal Contralateral Kidneys. Urology 2008;71:713-7.

19. Gadzinski AJ, Roberts WW, Faerber GJ, et al. Long-Term Outcomes of Nephroureterectomy Versus Endoscopic Management for Upper Tract Urothelial Carcinoma. J Urol 2010;183:2148-53.

20. Raymundo EM, Lipkin ME, Bañez LB, et al. Third prize: The role of endoscopic nephron-sparing surgery in the management of upper tract urothelial carcinoma. J Endourol 2011;25:377-84.

21. Metcalfe M, Wagenheim G, Xiao L, et al. Induction and Maintenance Adjuvant Mitomycin C Topical Therapy for Upper Tract Urothelial Carcinoma: Tolerability and Intermediate Term Outcomes. J Endourol 2017;31:946-53.

22. Grasso M, Fishman AI, Cohen J, et al. Ureteroscopic and extirpative treatment of upper urinary tract urothelial carcinoma: A 15-year comprehensive review of 160 consecutive patients. BJU Int 2012;110:1618-26.

23. Orihuela E, Smith AD. Percutaneous treatment of transitional cell carcinoma of the upper urinary tract. Urol Clin North Am 1988;15:425-31.

24. Goel MC, Mahendra V, Roberts JG. Percutaneous management of renal pelvic urothelial tumors: Long-term followup. J Urol 2003;169:925-9.

25. See WA. Continuous antegrade infusion of adriamycin as adjuvant therapy for upper tract urothelial malignancies. Urology 2000;56:216-22.

26. Elliott DS, Blute ML, Patterson DE, et al. Long-term follow-up of endoscopically treated upper urinary tract transitional cell carcinoma. Urology 1996;47:819-25.

27. De Kock MLS, Breytenbach IH. Local excision and topical thiotepa in the treatment of transitional cell carcinoma of the renal pelvis: A case report. J Urol 1986;135:566-7.

28. Martínez-Piñeiro JA, García Matres MJ, Martínez-Piñeiro L. Endourological treatment of upper tract urothelial carcinomas: Analysis of a series of 59 tumors. J Urol 1996;156:377-85.

29. Katz MH, Lee MW, Gupta M. Setting a new standard for topical therapy of upper-tract transitional-cell carcinoma: BCG and interferon- $\alpha 2 B$. J Endourol 2007;21:374-7.

30. Shapiro EY, Lipsky MJ, Cha DY, et al. Outcomes of intrarenal bacillus calmette-Guerrin/interferon-2B $\alpha$ for biopsy-proven upper-tract carcinoma in situ. J Endourol 2012;26:1645-50.

31. Smith AD, Orihuela E, Crowley AR. Percutaneous management of renal pelvic tumors: A treatment option in selected cases. J Urol 1987;137:852-6.

32. Schoenberg MP, Van Arsdalen KN, Wein AJ. The management of transitional cell carcinoma in solitary renal units. J Urol 1991;146:700-2.

33. Eastham JA, Huffman JL. Technique of mitomycin $\mathrm{C}$ instillation in the treatment of upper urinary tract urothelial tumors. J Urol 1993;150:324-5.

34. Vasavada SP, Streem SB, Novick AC. Definitive tumor resection and percutaneous bacille Calmette-Guérin for management of renal pelvic transitional cell carcinoma in solitary kidneys. Urology 1995;45:381-6.

35. Keeley FX, Bagley DH. Adjuvant mitomycin C following endoscopic treatment of upper tract transitional cell carcinoma. J Urol 1997;158:2074-7.

36. Patel A, Fuchs GJ. New techniques for the administration of topical adjuvant therapy after endoscopic ablation of upper urinary tract transitional cell carcinoma. J Urol 1998;159:71-5.

37. Clark PE, Streem SB, Geisinger MA. 13-year experience with percutaneous management of upper tract transitional cell carcinoma. J Urol 1999;161:772-5.

38. Thalmann GN, Markwalder R, Walter B, et al. Longterm experience with bacillus Calmette-Guerin therapy of upper urinary tract transitional cell carcinoma in patients not eligible for surgery. J Urol 2002;168:1381-5.

39. Palou J, Piovesan LF, Huguet J, et al. Percutaneous nephroscopic management of upper urinary tract 
transitional cell carcinoma: Recurrence and long-term followup. J Urol 2004;172:66-9.

40. Rastinehad AR, Ost MC, VanderBrink BA, et al. A 20Year Experience With Percutaneous Resection of Upper Tract Transitional Carcinoma: Is There an Oncologic Benefit With Adjuvant Bacillus Calmette Guérin Therapy? Urology 2009;73:27-31.

41. Giannarini G, Kessler TM, Birkhäuser FD, et al. Antegrade perfusion with bacillus calmette-Guérin in patients with non-muscle-invasive urothelial carcinoma of the upper urinary tract: Who may benefit? Eur Urol 2011;60:955-60.

42. Aboumarzouk OM, Somani B, Ahmad S, et al. Mitomycin $\mathrm{C}$ instillation following ureterorenoscopic laser ablation of upper urinary tract carcinoma. Urol Ann 2013;5:184-9.

43. Sharpe JR, Duffy G, Chin JL, et al. Intrarenal bacillus Calmette-Guerin therapy for upper urinary tract carcinoma in situ. J Urol 1993;149:457-9.

44. Yokogi H, Wada Y, Mizutani M, et al. Bacillus CalmetteGuerin perfusion therapy for carcinoma in situ of the upper urinary tract. Br J Urol 1996;77:676-9.

45. Nishino Y, Yamamoto N, Komeda H, et al. Bacillus Calmette-Guerin instillation treatment for carcinoma in situ of the upper urinary tract. BJU Int 2000;85:799-801.

46. Nonomura N, Ono Y, Nozawa M, et al. Bacillus CalmetteGuerin perfusion therapy for the treatment of transitional cell carcinoma in situ of the upper urinary tract. Eur Urol 2000;38:701-4.

47. Okubo K, Ichioka K, Terada N, et al. Intrarenal bacillus Calmette-Guérin therapy for carcinoma in situ of the upper urinary tract: Long-term follow-up and natural course in cases of failure. BJU Int 2001;88:343-7.

48. Irie A, Iwamura M, Kadowaki K, et al. Intravesical instillation of bacille Calmette-Guérin for carcinoma in situ of the urothelium involving the upper urinary tract using vesicoureteral reflux created by a double-pigtail catheter. Urology 2002;59:53-7.

49. Miyake H, Eto H, Hara S, et al. Clinical outcome of bacillus Calmette-Guérin perfusion therapy for carcinoma in situ of the upper urinary tract. Int J Urol 2002;9:677-80.

50. Hayashida Y, Nomata K, Noguchi M, et al. Long-term effects of bacille calmette-guérin perfusion therapy for treatment of transitional cell carcinoma in situ of upper urinary tract. Urology 2004;63:1084-8.

51. Kojima Y, Tozawa K, Kawai N, et al. Long-term outcome of upper urinary tract carcinoma in situ: Effectiveness of nephroureterectomy versus bacillus Calmette-Guérin therapy. Int J Urol 2006;13:340-4.
52. Lamm DL, Blumenstein BA, Crissman JD, et al. Maintenance bacillus Calmette-Guerin immunotherapy for recurrent Ta, T1 and carcinoma in situ transitional cell carcinoma of the bladder: A randomized Southwest Oncology Group study. J Urol 2000;163:1124-9.

53. Herr HW. Durable response of a carcinoma in situ of the renal pelvis to topical bacillus Calmette-Guerin. J Urol 1985;134:531-2.

54. Audenet F, Traxer O, Bensalah K, et al. Upper urinary tract instillations in the treatment of urothelial carcinomas: A review of technical constraints and outcomes. World J Urol 2013;31:45-52.

55. Motamedinia P, Keheila M, Leavitt DA, et al. The Expanded Use of Percutaneous Resection for Upper Tract Urothelial Carcinoma: A 30-Year Comprehensive Experience. J Endourol 2016;30:262-7.

56. Redrow GP, Guo CC, Brausi MA, et al. Upper Urinary Tract Carcinoma In Situ: Current Knowledge, Future Direction. J Urol 2017;197:287-95.

57. Traxer O, Bogdan G, de Medina SG diez, et al. Narrowband imaging digital flexible ureteroscopy in detection of upper urinary tract transitional cell carcinoma: initial experience. J Endourol 2011;25:19-23.

58. Somani BK, Moseley H, Eljamel MS, et al. Photodynamic diagnosis (PDD) for upper urinary tract transitional cell carcinoma (UT-TCC): Evolution of a new technique. Photodiagnosis Photodyn Ther 2010;7:39-43.

59. Ahmad S, Aboumarzouk O, Somani B, et al. Oral 5 -aminolevulinic acid in simultaneous photodynamic diagnosis of upper and lower urinary tract transitional cell carcinoma - A prospective audit. BJU Int 2012;110:E596-600.

60. Kata SG, Aboumarzouk OM, Zreik A, et al. Photodynamic diagnostic ureterorenoscopy: A valuable tool in the detection of upper urinary tract tumour. Photodiagnosis Photodyn Ther 2016;13:255-60.

61. Sfakianos JP, Cha EK, Iyer G, et al. Genomic Characterization of Upper Tract Urothelial Carcinoma. Eur Urol 2015;68:970-7.

62. Moss TJ, Qi Y, Xi L, et al. Comprehensive Genomic Characterization of Upper Tract Urothelial Carcinoma. Eur Urol 2017;72:641-9.

63. Audenet F, Isharwal S, Cha EK, et al. Clonal relatedness and mutational differences between upper tract and bladder urothelial carcinoma. Clin Cancer Res 2019;25:967-76.

64. Rouprêt M, Azzouzi AR, Cussenot O. Microsatellite instability and transitional cell carcinoma of the upper urinary tract. BJU Int 2005;96:489-92. 
65. Catto JWF, Azzouzi AR, Rehman I, et al. Promoter hypermethylation is associated with tumor location, stage, and subsequent progression in transitional cell carcinoma. J Clin Oncol 2005;23:2903-10.

66. Cancer Genome Atlas Research Network. Comprehensive molecular characterization of urothelial bladder carcinoma. Nature 2014;507:315-22.

67. Matin SF, McConkey DJ. Bridging the Gap in Upper Tract Urothelial Carcinoma. Eur Urol 2015;68:978-9.

68. Bagrodia A, Audenet F, Pietzak EJ, et al. Genomic Profile of Urothelial Carcinoma of the Upper Tract from Ureteroscopic Biopsy: Feasibility and Validation Using Matched Radical Nephroureterectomy Specimens. Eur Urol Focus 2019;5:365-8.

69. Schmittgen TD, Wientjes MG, Badalament RA, et al. Pharmacodynamics of Mitomycin C in Cultured Human Bladder Tumors. Cancer Res 1991;51:3849-56.

70. De Bruijn EA, Sleeboom HP, van Helsdingen PJRO, et al. Pharmacodynamics and pharmacokinetics of intravesical

Cite this article as: Metcalf M, Pierorazio PM. Future strategies to enhance kidney preservation in upper urinary tract urothelial carcinoma. Transl Androl Urol 2020;9(4):1831-1840. doi: 10.21037/tau.2019.11.09 mitomycin $\mathrm{C}$ upon different dwelling times. Int J Cancer 1992;51:359-64.

71. Barros AA, Browne S, Oliveira C, et al. Drug-eluting biodegradable ureteral stent: New approach for urothelial tumors of upper urinary tract cancer. Int J Pharm 2016;513:227-37.

72. Lim WS, Chen K, Chong TW, et al. A bilayer swellable drug-eluting ureteric stent: Localized drug delivery to treat urothelial diseases. Biomaterials 2018;165:25-38.

73. Smith AY, Vitale PJ, Lowe BA, et al. Treatment of superficial papillary transitional cell carcinoma of the ureter by vesicoureteral reflux of mitomycin C. J Urol 1987;138:1231-3.

74. Kleinmann N, Pierorazio P, Matin S, et al. LBA25 Non-Surgical Management of Low Grade Upper Tract Urothelial Cancer: An Interim Analysis of the International Multicenter OLYMPUS Trial (NCT02793128). J Urol 2018;199:e1166. 